\title{
Ouvir para se poder olhar dentro da clínica do autismo. De onde vem a voz que me faz existir?
}

Chantal Lheureux-Davidse*1

As crianças autistas ficam frequentemente absorvidas na procura de sensações que as façam sentir existir. Ela evitam o vínculo direto e não podem interiorizar uma segurança de ser. O lugar do terapeuta numa atenção cuidadosa, no ritmo da criança, fazendo imitações e comentários narrativos sobre o vivido da criança ajuda a despertar um sentimento de existir e um interesse pelo outro.

É a voz que atrai a atenção da criança, quando ela se integra de modo alegre e ritmado às emoções e aos interesses sensoriais ou estéticos da criança. A procura espontânea pela voz na origem dos comentários ajuda a criança a descobrir um interesse pelo olhar direto no rosto do outro.

Palavras-chave: Autismo, narração, voz, olhar

${ }^{* 1}$ Université Paris 7 - Denis Diderot (Paris, França). 


\section{ARTIGO}

Uma das características dos distúrbios autistas é o evitamento do olhar direto e de todos os movimentos imprevisíveis de um rosto em particular, como os movimentos expressivos espontâneos que, no entanto, caracterizam os humanos.

Proponho refletir com vocês sobre a questão do visual no encontro de uma pessoa autista com uma outra pessoa, e sobre a articulação entre o visual e o auditivo.

Colocarei em destaque a participação do sonoro e da voz do analista para articular o sonoro ao visual no encontro com uma pessoa autista.

$\mathrm{Na}$ maior parte das vezes, os efeitos de clivagem nas pessoas autistas geram uma desmontagem sensorial, que se caracteriza pelo fato de que um só sentido funciona de cada vez: seja o olfato ou a gustação, seja o tato, a audição, a visão ou a busca de equilíbrio no corpo, fazendo com que os sentidos não se revezem e nem se articulem entre si.

Tomarei como exemplo algumas passagens do acompanhamento de uma menina autista, Delphine, sem linguagem verbal, que evitava o olhar direto há anos, até que o acompanhamento terapêutico progressivamente o tornou possível.

Interrogarei, particularmente, o papel da voz do terapeuta na descoberta progressiva da criança autista de um interesse espontâneo pelas trocas de olhar face a face, sem que o terapeuta induza-a a isto, o que poderia ser vivido como uma efração intrusiva.

O olhar direto de uma criança autista na presença de um outro é frequentemente como um olhar cego. O olhar periférico será normalmente utilizado até que uma certa confiança tenha se desenvolvido. 


\section{Hipersensibilidade e efração sonora}

Delphine é uma menina autista sem qualquer linguagem verbal. Ela não emitia o menor som quando eu a vi pela primeira vez. Seu olhar no rosto não existia. Era patético vê-la quando era pequenininha, frequentemente em lágrimas numa situação em grupo sem emitir o menor som que fosse, o que parecia colocá-la num estado de liquefação. Ela passava, a propósito, muito tempo retorcida sobre si mesma numa hipotonia axial que a impedia de tornar-se disponível ao seu ambiente.

Quando ela se movimenta numa lentidão extrema, seu corpo, de aparência frágil, se põe em movimento de forma delicada. Esta lentidão parece-lhe permitir aproveitar de cada movimento, de cada mudança, e de destilar as sensações e as emoções vividas em um tempo dilatado de modo a torná-las integráveis aos poucos e como para evitar todo e qualquer imprevisto, que seria vivido como uma efração. A intensidade, assim como a velocidade, são rapidamente muito fortes para sua hipersensibilidade. O que também é o caso para outras crianças autistas segundo os textos de Bruno Gepner (2014).

Parece que ele só consegue seguir uma coisa de cada vez. Fica, então, inteiramente absorta pela sensação do momento, excluindo todo o resto do seu campo de consciência, num estado de desmontagem sensorial descrito por Donald Meltzer (1980). Suas pernas ficam ligeiramente arqueadas quando ela está de pé, como se para permitir um melhor apoio para o corpo. Ela se movimenta lentamente como se estivesse num meio aquático ou num estado de leveza.

Com frequência manifesta dificuldade em suportar o vaivém e o blá-blá-blá de um grupo. A percepção do barulho e dos deslocamentos dos demais é a tal ponto insuportável que ela tapa as orelhas com seus punhos. Punhos estes que ela frequentemente automutila arrancando a pele, como se estivesse despertando as sensações esquecidas de seu corpo por meio de seus antebraços que ligam, ainda que com dificuldade, suas mãos ao resto do corpo.

Ela cuidadosamente evita o encontro direto e particularmente o olhar. Ela se auto organiza em seu mundo, em seus comportamentos muito repetitivos e restritos, aos quais se agarra como que para tranquilizar-se, mas que excluem todo e qualquer interesse pelo novo ou pelo encontro com outrem.

\section{Desmantelamento sensorial e dissociação}

O desmantelamento sensorial descrito por Donald Meltzer (1980) tem uma primeira função defensiva de apaziguamento das vivências sensoriais quando 


\section{ARTIGO}

estas são intensas ou intrusivas demais, na medida em que uma paraexcitação, ou uma função continente, não esteja ainda interiorizada. $\mathrm{O}$ desmantelamento rompe os sentidos ao fragmentá-los em sensações esparsas, desagregando a articulação existente entre eles. Cada sensação que não pode mais coexistir com outra funciona de forma isolada e difrata a intensidade da globalidade das experiências que eram adequadas, quando os sentidos estavam ligados numa experiência intensa demais.

Esta dissociação dos sentidos, nas pessoas autistas, provoca uma perda no ajustamento global a uma situação, ou a um contexto e, por conseguinte, traz uma perda de ligação em outros domínios além do sensorial: perda de associação entre os pensamentos, entre as palavras, entre as sílabas para aqueles que falam, perda de articulação entre as experiências corporais oriundas de diferentes partes do corpo, o qual não é mais vivido em sua integralidade, perda de articulação com elementos temporais vividos naquele instante mesmo, mas que não estão mais associados a um passado nem a um futuro.

A perda do ajuste nas direções do espaço pode igualmente fazer ressonância com o desmantelamento sensorial chegando a uma experiência de caos interno, mas sem que este se instale de forma psicótica.

\section{Aderência sensorial e objeto autístico}

Nestes estados de flutuação em que nada mais está ligado, o risco de perda do sentimento de existir pode tornar-se invasivo e produzir pânico. Para evitar estas angústias agonizantes, a urgência em constatar o sentimento de existir em seu corpo pode se manifestar de forma imperativa através de uma procura sensorial (Lheureux-Davidse, 2005). O espaço não é mais vivido em volume nestes momentos. $\mathrm{E}$ a abordagem do ambiente se limita a contatos de superfície.

A escolha da aderência sensorial se focaliza, então, na vertente da sensação a mais atraente, que se origina com frequência de uma sensação familiar, facilmente mobilizada e controlada. É num recurso aos estereótipos habituais ou ao seu objeto autístico predileto, objetos estes que transmitem sensações reanimadoras, que a pessoa autista se refugia. Esta sobrevive psiquicamente, uma vez que ela se reconhece de modo solitário através das sensações e emoções que assim obtém.

Delphine, por exemplo, utiliza seu objeto autístico em momentos de pânico ou de transbordamento. Trata-se de um ratinho mecânico recoberto de um tecido de pelúcia que vibra quando acionado o mecanismo; ela o coloca sobre a ponta do nariz e olha-o fazendo-se de vesga. Ela mergulha no olhar do ratinho que ganha 
vida pelas vibrações mecânicas e que produzem também um ruído surdo e que pode ser percebido de perto. Seu rosto se reanima repentinamente em êxtase com um sorriso de felicidade. Ela começa a arregalar os olhos e sobrancelhas com esta experiência maravilhosa que possui o dom de apaziguá-la imediatamente. Ela usufrui então de modo autístico de uma união de todas as experiências sensoriais num movimento de remontagem provisória e instantânea em que o olfato, o sonoro, o tátil e a visão coexistem como num bebê no momento de relação de proximidade com sua mãe. $\mathrm{O}$ eixo vertical do corpo aparece mais tonificado nestes momentos.

Durante os trajetos, ela se focaliza sobre seu objeto autístico que ela aciona sobre a ponta do nariz, o que lhe permite continuar a andar sem experimentar o abismo da profundidade de campo no espaço, que de outra forma a impediria de avançar. Nós a guiamos então, em sua trajetória, seja por colagem em hemicorpo, ou graças ao fato de que ela nos capta pela visão periférica lateral ao mesmo tempo que se apoia em paralelo em nossa trajetória.

\section{Um espaço sem borda e deslocamentos rápidos demais}

Da mesma forma como uma criança autista evita o olhar direto, ela evita particularmente o olhar face a face com os outros, apesar de este olhar ser constitutivo da relação e da noção de profundidade de campo no espaço. Ao evitar o olhar de frente, o ajustamento focal não se desenvolve, comprometendo, assim, a avaliação de distâncias no espaço.

A má avaliação de distâncias no espaço tornam os deslocamentos problemáticos, pois um movimento ou um deslocamento no espaço privado da dimensão e da profundidade pode ser inquietante, por ser experienciado seja em sua bidimensionalidade, seja como um espaço de cegueira imprecisa, sem fundo e sem borda.

E é por isso que os deslocamentos das pessoas diante de uma criança autista lhe parecem um tanto enlouquecedores. Sua dificuldade em avaliar a distância é reforçada pela rapidez ou pela surpresa de um deslocamento por demais brusco. Os movimentos fluidos e lentos (Lheureux-Davidse, 2004) são preferíveis por serem mais facilmente controláveis e antecipáveis. Por essa razão, ela se interessa muito mais por um ambiente não humano inanimado e tenta colocá-lo em movimento sob seu controle. O ambiente inanimado é preferível ao mundo humano, o qual lhe parece imprevisível em suas mudanças e movimentos.

Além do mais, as pessoas autistas investem demasiado os detalhes não humanos, o que as tornam mais performantes do que nós para percebê-los. Mas, 


\section{ARTIGO}

assim o fazem em detrimento do reconhecimento de detalhes de expressão de um rosto e de uma percepção da articulação dos detalhes, como demonstrado por Laurent Mottron (2004).

A aderência a uma sensação de proximidade, como o que acontece durante um contato de superfície com uma sensação olfativa, tátil ou gustativa, pode servir de tábua de salvação em um espaço cuja profundidade é dificilmente avaliada rapidamente.

$\mathrm{O}$ recurso à adesividade real ou psíquica a um objeto, de uma sensação, de uma luz ou de um movimento, ou de vez em quando a um duplo imaginário, torna-se uma solução na premência para tentar evitar desmoronar num espaço experienciado como um buraco sem fundo.

\section{Remontagem sensorial autística}

Assim, pelo contato adesivo direto com seu objeto autístico, que é o ratinho mecânico, Delphine mantém vibrações sonoras e visuais (Lheureux-Davidse, 2007), como para se manter em contato consigo mesma pelo eixo vertical de seu nariz. Ela obtém um efeito visual e sonoro de micromovimentos que animam os olhos brilhantes de seu ratinho e que ela pode olhar de perto e diretamente, numa comodalidade sensorial. Com um grande sorriso e elevando as sobrancelhas maravilhada, ela se surpreende ao descobri-lo a cada vez.

Esses momentos de reencontros com seu objeto autístico dão-lhe acesso imediatamente a sensações múltiplas em uma comodalidade sensorial, que Meltzer chamaria de remontagem sensorial, na qual todos os sentidos funcionariam ao mesmo tempo. O lucro obtido é um ganho de sentimento de existência, como aquele que um bebê vivencia nos momentos em que mama na mãe. Mas, enquanto esta experiência de comodidade sensorial for vivenciada de forma autística, ela não se inscreve psiquicamente e permanece num estado de traço sensorial não mobilizável em sua duração.

Dessa forma, o ganho obtido em sentimento de existir, efetivo naquele instante, deve ser renovado frequentemente, como o que acontece durante os movimentos repetitivos de estereotipias ou de utilização de um objeto autístico para dar impressão de continuidade. Pois o sentimento contínuo de existir está excluído quando há clivagem e dispersão psíquicas, como acontece no autismo. Apesar da ausência de ligação com o ambiente, a soma das experiências instantâneas de remontagem sensorial e de reencontros consigo mesmo cria uma ilusão de sentimento de continuidade de ser, em pontilhado, mas que não se articula, nem se integra sem a presença de vínculo a um outro. 
Os momentos de reencontro com o sentimento de existir são, de toda forma, necessários. Mas o processo repetitivo que busca sensações reforça, no entanto, o confinamento autístico, até que alguém se interesse mais detidamente pelo fato. Essa remontagem sensorial permanece, entretanto, instantânea e autista.

\section{Observação, imitação e comentários narrativos}

É no contexto de alternância de desmontagem sensorial, e de momentos de aderência sensorial autística da criança, que o terapeuta tenta tornar compartilháveis estados, até então, sem vínculo para a criança. O terapeuta torna-se um apoio continente com o qual a criança poderá comunicar-se em seguida. É assim que a aderência sensorial pelo contato de superfície, por exemplo, seja ele real ou psíquico, e que exclui todo e qualquer outro interesse por aquilo que é diferente, cederá o lugar à construção de um sentimento de existir num limite corporal continente, na diferença, graças ao vínculo continente que o terapeuta oferece.

O mundo de sensações no qual Delphine deambula parece ser seu único centro de interesse. E, no entanto, é quando o investimento humano é privilegiado em detrimento de um ambiente inanimado não humano, que um traço psíquico pode ter duração e que as experiencias sensoriais ou emocionais podem ser refletidas pelo espelho identificatório que o outro representa.

Trata-se, pois, de nos identificarmos com Delphine em seu tempo tão lento, com as sensações mais arcaicas que ela busca e às quais se apega, para permitir-lhe ser reconhecida como sujeito vivenciando tais sensações ou emoções. É o que lhe dará o sentimento de existir na relação com o outro. Isto torna-se possível pela observação cuidadosa, pela imitação ou pelos comentários narrativos sobre suas vivências e mudanças que ela tem dificuldade para compreender.

Nossa sintonia como terapeuta com o ritmo de integração sensorial da criança faz-se necessária. Isto exige, em certos momentos, uma diminuição extrema de nosso ritmo e de nossa velocidade habitual. Essa afinação provoca na criança experiências espontâneas de reinvestimento do vínculo e particularmente do olhar: encontros tão intensos quanto breves num primeiro tempo.

\section{Ritmicidade e distância}

A alternância de momentos de desmantelamento e momentos de encontros dá acesso a um esboço de diferenciação, que implica que encontro e separação se façam ao ritmo da criança, com flexibilidade, sem pânico nem colapso. 


\section{ARTIGO}

A aderência sensorial que equivale a uma sensação de contato de superfície que abole distâncias e profundidade de campo se abre de vez em quando a um interesse por sensações de distância a partir do visual, o que faz supor que um espaço e uma separação possam ser suportáveis.

Suzanne Maiello $(1997,2000,2004)$ chamou a atenção, em seus trabalhos, sobre a passagem de sensações de proximidade (tais como o olfato e o tato) às sensações de distância (como o visual). Essa passagem impõe a aceitação de uma distância de separação que não mais provoca uma experiência de arrancar a pele comum. Ela sublinha o quanto a sensação sonora rítmica favoriza, no vínculo ao outro, essa passagem entre sensação de proximidade e sensação de distância. Seria então a experiência sonora pela alternância de colagem e de descolagem repetida de modo rítmico, experiência significativa e emocionalmente compartilhada, que provocaria um interesse pelo visual, não mais passando pela aderência mas, antes, pelo desenvolvimento da noção de volume no espaço.

Em uma série de sessões com Delphine, seu olhar fica evasivo, flutuante e parecendo ausente; seu corpo parece pouco habitado devido à falta de tônus. As situações de grupo ao longo do dia lhe são particularmente peníveis, pois lhe fazem esquecer sua existência corporal, ao ponto de se automutilar para se lembrar da existência. Ela golpeia as orelhas com seus punhos no momento em que ouve o blá-blá-blá imprevisível. Em outros momentos ela arranca a pele dos pulsos como se assim mantivesse a existência da ligação de suas mãos ao resto do seu corpo.

Ao longo da terapia, eu comento a menor sensação que observo que ela experimenta; o menor movimento ou a menor emoção que transpareça e parece atravessá-la. Pois nenhuma experiência pode ser psiquicamente inscrita pelo simples fato de durar. Sua expressão corporal e a de seu rosto pouco deixam transparecer suas sensações e suas vivências internas. Os estados emocionais que ela me faz vivenciar por identificação me fornecem indicações preciosas.

\section{Vibrações e emoções estéticas}

Delphine parece sempre contente ao entrar para a sessão a cada vez que vou buscá-la. Meus comentários parecem juntar-se na maioria das vezes aos seus traços sensoriais dispersos, sem que estes possam ainda articular-se, e sem que Delphine possa se mobilizar imediatamente. Suas reações são ainda dispersas, e ela precisa de tempo para perceber que me dirijo a ela e para responder-me.

Delphine reage particularmente às vibrações do ambiente que parecem tranquilizá-la, como numa experiência familiar. Com essas vibrações, sejam quais 
forem suas origens, ela torna-se viva, tonificada, comunicativa e menos lenta. Ela mordisca os lábios, ao mesmo tempo que retorce o nariz, como se isto traduzisse os benefícios das vibrações obtidas com o ratinho mecânico em seu nariz.

Meus comentários começam a fazer o mesmo efeito que fazem as vibrações que ela escuta ao acaso de um ônibus que passa ou do cortador de grama que ronrona. Comento as vivências das quais ela começa a tomar consciência dessa forma, para compartilhar de seus interesses. Ela me lança olhares furtivos, especialmente quando eu não a estou olhando, controlando, dessa forma, as trocas para que elas não sejam imprevisíveis demais.

Certa vez, enquanto seu olhar flutuava, ela apegou-se visualmente, e de maneira adesiva, a uma forma geométrica luminosa muito contrastante, desenhada por um raio de sol sobre a parede que nos liga visual e perifericamente de lado. Essa forma luminosa contrastante e magnífica me surpreende ao ponto de compartilhar com ela, por meio de meus comentários e pela minha voz emocionalmente eloquente, essa emoção estética (Meltzer, 2000) diante da beleza da geometria dessa forma luminosa.

As crianças autistas são muito sensíveis às emoções estéticas que ressoam com emoções profundas, suscitadas pelas suas formas internas em formação. É esse meio que nos permite juntar-nos a elas em seus mundos quando por isto nos interessamos.

\section{Atenção conjunta e primeiros sons}

Após meus comentários sobre a bela forma luminosa sobre a parede, na qual o seu olhar se adere, o rosto de Delphine se ilumina e exprime todo o encantamento que ela experimenta, ao que parece, de forma interna. Eu escuto o som de sua voz pela primeira vez, pois Delphine lança espontaneamente um som ritmado de "ah ah ah!" abrindo a boca em direção à forma luminosa, e avançando a cabeça em direção da luz como se ela acompanhasse com o seu movimento de cabeça essa substância sonora que ela ousa deixar sair de sua boca. Em seguida, lança um olhar em minha direção num júbilo compartilhado. Trocamos um momento de cumplicidade magnífica e tranquila diante de uma luz que nós olhamos com atenção conjunta. Sabemos o quanto os momentos de atenção conjunta constituem um progresso no estabelecimento de uma relação com uma criança autista (Becache, Bursztejn, Danion-Grillat, 1997).

Quando uma criança autista está imersa numa vivência sensorial ou emocional, ela normalmente não tem uma demanda ou mesmo uma expectativa de que um outro possa compartilhar esse momento. As estereotipias das crianças 
autistas frequentemente não são compreendidas por aqueles que as cercam. Suas características restritivas e repetitivas provocam mais rejeição do que atenção e, menos ainda, um encantamento compartilhado.

Assim as estereotipias e os movimentos restritos autossensoriais parecem excluir o outro e se automantêm sem, contudo, desenvolver o menor sentimento de existir que possa perdurar. É por essa razão que a criança autista nunca cessa, a cada instante, de repeti-los.

\section{Emoção, direção da voz e visão}

Quando um comentário cria uma narrativa (Hochmann, 2009) e reconhece a criança em suas vivências autistas, é com frequência a sonoridade da voz que produz o gancho relacional antes que o visual possa ser encontrado no vínculo com o outro. Não são as emoções que veiculam a voz em sua autenticidade e união, em ressonância com as vivências da criança, que tornam isto possível?

Os trabalhos de Colwyn Trevarthen (1997) nos deram numerosos exemplos dos primeiros diálogos entre a mãe ou o pai e o bebê, tanto pela escanção quanto pelo ritmo e frequência, altura da voz, quando o diálogo está investido com emoção.

Da mesma forma, após um comentário identificatório que lhe seja dirigido numa sintonia de emoções que lhe falam, ou após uma imitação de seus gestos (Nadel, 2002, 2011) que um outro possa fazer a uma certa distância numa função identificatória não invasiva, a criança autista se vira na direção da voz que está na origem da tomada de consciência de sua existência. É o ajuste na simetria da orientação de sua cabeça em relação à direção de onde provém o som da voz que a faz descobrir em seguida que essa voz pertence a uma boca, a um rosto e mesmo a uma pessoa. Nós assistimos a uma experiência de descoberta do rosto e em seguida um mergulho no olhar do outro graças ao conteúdo sonoro da voz que foi o chamariz. É assim que se reconstitui uma dupla ligação de uma interpenetração de olhares e de encontros de vínculos com a boca que comenta e que dá um equivalente do leite bom.

Não é raro observar em outras crianças autistas momentos similares durante os quais elas fazem movimentos de mamar com a boca, como se para ajustarem-se, por identificação, aos movimentos da boca do terapeuta que fornece esses comentários identificatórios.

Dessa forma, poderíamos dizer que se trata da voz do terapeuta em seus comentários, investidos a partir das emoções e da vivência da criança, que transmodaliza do sentido auditivo para a visão. A visão é um sentido mais elaborado, pois ela impõe uma distância separadora. Ela é o novo e o último dos sentidos 
experimentados após o nascimento, mesmo estando potencialmente funcional desde os primeiros meses da gravidez. Esse deslocamento de um sentido para outro, numa transmodalidade sensorial, participa tanto do estabelecimento de experiências de encontros diretos quanto de um momento de união dos sentidos e de remontagem sensorial, em que audição e visão não são excludentes.

São momentos estruturantes para a construção do sentimento de existir e para a instalação de um vínculo. Eles participam de um encontro por vir que somente se estabelecerá na diferenciação e na separação, à condição de que o buraco negro que Frances Tustin $(1982,1986)$ nos descreveu na história do pequeno paciente John não esteja forrado de espinhos vilões, mas de emoções acolhedoras nas quais a criança possa se reconhecer em seu ritmo.

\section{Imitação e ritmicidade}

Atualmente Delphine torna-se cada vez mais sensível às imitações que fazemos de seus gestos quando acompanhados de barulhos ou de comentários com ritmos alegres. Ela começa, como faria uma criancinha, a seguir as conversas ou as imitações que fazemos de seus gestos por buscas oculares. Juntamente com a estagiária que trabalha comigo durante as sessões de Delphine, não perdemos a oportunidade de provocar suas buscas oculares numa alternância entre o jogo que ela investe naquele momento e nós mesmas, nos colocando de um lado e do outro, ou seja, a sua esquerda e a sua direita.

Quando ela encontra-se absorta em seu jogo de misturar pequenos objetos numa bacia para assim obter pequenos ruídos continuamente, nós observamos que o interesse pelos ruídos externos, ou pelos comentários que produzimos, é mais atraente para ela do que as imitações de gestos não acompanhadas de produção sonora e que ela não se interessa pelo que fazemos se não for acompanhado de ritmicidade. Delphine reage fortemente a essa observação que formulo em voz alta. Isto a faz deixar espontaneamente seu jogo para me olhar longamente nos olhos com um grande sorriso. Seu olhar não é do tipo adesivo e demonstra uma verdadeira compreensão e uma comunicação que se instala, verbal do meu lado e não verbal do seu.

Ao fim da sessão ela vira a cabeça em nossa direção e não é mais o objeto sonoro que lhe causa interesse, mas o compartilhar emocional e visual na direção de nossos rostos. A necessidade do ajuste inicial do seu rosto na direção do som de minha voz, antes de poder descobrir visualmente meu rosto, não é mais necessário, ela pode me olhar diretamente agora. 


\section{ARTIGO}

Eu falo com frequência do seu objeto autístico e faço com que seu ratinho mecânico participe de modo lúdico naquilo que empreendemos. Ela começa a me confiar espontaneamente seu ratinho e esse objeto autístico assume nesses momentos um status de objeto transicional, divisível.

\section{Desenho e identificante duplo}

Eu desenhei muito seu ratinho. Desenho uma família de ratinhos e lhe ofereço um pincel convidando-a a participar. Ela aceita o pincel e rabisca por cima. Seus traços se superpõem ao desenho do ratinho filhote que eu havia feito.

Finalmente, olhando-a a fim de representá-la, eu desenhei o alto do seu rosto com o ratinho entre os dentes, seus olhos semiabertos observando seu ratinho sobre o seu próprio rosto. Eu vejo então a direção do seu olhar alternar entre os brinquedos que ela remexe na bacia e o desenho. Tão logo terminado o desenho, ela pega a folha e passa a folha sobre o lado do seu rosto, comparando o desenho sobre a folha e o seu próprio rosto, para que este efeito de duplo seja o mais preciso.

Ela alterna a observação periférica do desenho e a auto-observação do seu próprio rosto. Temos a impressão de uma primeira descoberta dela mesma como num espelho. Essa experiência de consciência de si mesma a partir de uma representação desenhada é emocionante. Ela própria está surpresa, se ajeita e divide seu júbilo olhando-nos espontaneamente numa troca alegre que nada tem de adesivo. E fico surpresa ao ouvi-la emitir alguns sons de contentamento comunicativo que passaram a acompanhar as sessões a partir de então.

$$
*
$$

Algumas crianças autistas hipersensíveis, sem linguagem verbal na evitação do encontro direto, como vimos no caso Delphine, ficam frequentemente absortas pela aderência a uma sensação familiar que produz um objeto autístico e lançam mão de automutilações para fazerem perdurar o sentimento de existência.

Para encontrarem o sentimento de existir, não de modo autista, mas numa relação com o outro e em seu próprio ritmo, nos interrogamos sobre o lugar do terapeuta em sua atenção cuidadosa, em suas imitações e em seus comentários narrativos a propósito das vivências da criança.

A voz do terapeuta é especialmente explorada, e são as emoções, em sintonia com o vivido pela criança, que mais atraem a sua atenção para a voz do terapeuta. Os comentários em relação à criança investidos com emoção despertam-lhe o interesse, fazendo sentir-se nomeada e existindo. Ela se vira então espontaneamente em direção da voz, e descobre um rosto e uma pessoa. 
O interesse pelo sonoro da voz do terapeuta se articula pela transmodalidade sensorial ao visual direto e favorece uma remontagem sensorial e o estabelecimento do vínculo.

Quando o visual não é mais investido unicamente em um vínculo adesivo como pela aderência sensorial, ele participa não somente no investimento do vínculo, mas igualmente em uma diferenciação entre si e o outro e na construção da noção de profundidade de espaço e de suas margens.

Enquanto o sentimento de existir rapidamente se desfaz, quando buscado de forma autista, pois se sustenta somente no instante mesmo, esse sentimento se constrói de forma mais sólida na durabilidade quando construído pelo vínculo ao outro, pois se estabelece ao mesmo tempo que a noção de continente, que favoriza a capacidade de interiorização e as inscrições psíquicas.

No caso de Delphine, a atenção conjunta acompanhada de comentários do terapeuta em face das emoções estéticas às quais ela foi sensível, sem no entanto poder representá-las, favoreceu o estabelecimento do vínculo e do olhar direto de modo espontâneo.

Quando os comentários do terapeuta, em atenção conjunta, são feitos de forma alegre e ritmada, uma busca ocular é mais facilmente provocada. Igualmente, quando a imitação vem acompanhada de ritmicidades sonoras, o investimento do vínculo direto se estabelece com maior facilidade.

Dessa forma, a voz do terapeuta participa, em seus comentários carregados de emoções dispensadas à vivência da criança, no reinvestimento espontâneo do vínculo visual da criança em direção ao rosto do outro. Na sequência, a criança olha espontaneamente com mais frequência para o rosto do outro sem necessidade de passar por ritmos sonoros ou comentários. Quando a criança autista pode aproveitar da voz do terapeuta para se sentir existindo, ela pode, então, aproveitar-se do olhar do terapeuta como um espelho identificatório.

Agradeço a Paulo Fonseca pela tradução do francês para o português.

\section{Referências}

Becache, E.; Bursztejn, C.; \& Danion-Grillat, A. (1997). Valeur de l'attention conjointe et du pointage dans l'autisme: Une absence à remarquer. Cognition et développement: un nouveau regard sur la psychopathologie de l'enfant. Neuropsychiatrie de l'enfance et de l'adolescence, 45(10), 584-591.

Gepner, B. (2014). Ralentir le monde extérieur, calmer le monde intérieur. Paris: Odile Jacob. 
Hochmann, J. (2009). Histoire de l'autisme. De l'enfant sauvage aux troubles envahissants du développement. Paris: Odile Jacob.

Lheureux-Davide, Ch. (2003). L'autisme infantile ou le bruit de la rencontre. Contribution à une clinique des processus thérapeutiques. Paris: L'Harmattan, $342 \mathrm{p}$.

Lheureux-Davide, Ch. (2004, Mars). La reconstruction de l'image de corps de Léo, enfant trisomique avec des retraits autistique. Cliniques Méditerranéennes, 69, 289-308.

Lheureux-Davidse, Ch. (2005, Mai). Autisme et addictions. L'Informe et l'Archaïque, Recherches en psychanalyse, 3, 31-42.

Lheureux-Davidse, Ch. (2007). Jouer avec les mouvements, les vibrations et les rythmes dans l'émergence de la voix. Champ Psychosomatique, La Voix, 48, 185-203.

Lheureux-Davidse, Ch. (2013). Regard, traitement de l'espace et particularités de la pensée des personnes autistes. In Autismes et psychanalyse (pp. 141-172). Paris: Eres.

Maiello, S. (1997). L'objet sonore. Hypothèse d'une mémoire auditive prénatale. Le corps. Journal de psychanalyse de l'enfant, 20, 40-66.

Maiello, S. (2000), Trames sonores et rythmiques primordiales. Réminiscences auditives dans le travail psychanalytique. La croissance psychique. Journal de la psychanalyse de l'enfant, 26, 77-104.

Maiello, S. (2004). Le "chant et danse" et son développement: la fonction du rythme dans le processus d'apprentissage du langage oral et écrit. Langages. Journal de psychanalyse de l'enfant, 35, 149-170.

Meltzer, D.W.; Bremner, J.; Hoxter, S.; \& Wittenberg, I. (1980). Explorations in Autism, trad. Fr. Explorations dans le monde de l'autisme, The Roland Harris Educational Trust, 266p.

Meltzer, D.W., \& Williams, M.H. (2000). L'appréhension de la beauté. Le conflit esthétique, son rôle dans le développement, la violence, l'art. Larmor-plage: Editions du Hublot.

Mottron, L. (2004). L'autisme: une autre intelligence. Diagnostic, cognition et support des personnes autistes sans déficience intellectuelle. Sprimont (Belgique): Pierre Mardaga éditeur.

Nadel, J.; \& Decety, J. (2002). Imiter pour découvrir l'humain, Psychologie, neurobiologie, robotique et philosophie de l'esprit. Paris: PUF.

Nadel, J. (2011). Imiter pour grandir. Développement du bébé et de l'enfant avec autisme. Paris: Dunod

Trevarthen, C. (1997). Racines du langage avant la parole. Devenir, 9(3), 73-93

Tustin, F. (1982). The Protective Shell in Children and Adults. Londres: Karnac Books.

Tustin, F. (1986). Autisme et Protection. Paris: Seuil.

Tustin, F. (1986), Autistic Barriers in Neurotic Patients. Londres: Karnac Books.

Tustin, F. (1989). Le trou noir de la psyché, Barrières autistiques chez les névrosés. Paris: Seuil.

Rev. Latinoam. Psicopat. Fund., São Paulo, 18(4), 634-650, dez. 2015 
Winnicott D. (1975), The fear of Breakdown. (Trad. J. Kalmanovitch \& M. Gribinski). La crainte de l'effondrement, Figures du vide. Nouvelle Revue de Psychanalyse, 11, 35-44. (Travail original publié en 1963).

\section{Resumos}

(Listening as a way of casting a look into the clinical experience involving autism. Where does the voice that makes me exist come from?)

Autistic children are often completely absorbed by going after sensations that make them feel they exist. They evade any direct bonding and are not able to internalize the security of being. The therapist can help the child feel that it exists and awake an interest for others by giving it careful attention, by following the child's pace, making imitations and comments on the child's experience.

It's the voice that attracts the child's attention, when it harmonizes joyously and rhythmically with the emotions and sensorial or aesthetical interests of the child. The spontaneous search for the origin of the voice that makes those comments awakes the child's interest in the direct gaze in the face of the other.

Key words: Autism, narrative, voice, gaze

(Ecouter pour pénétrer dans la clinique de l'autisme. D'où vient la voix qui me permet d'exister?)

Les enfants autistes sont souvent entièrement absorbés par la recherche de sensations qui leur permettent de sentir qu'ils existent. Ils évitent les liens directs et ne sont pas en mesure d'intérioriser la certitude d'exister. La place du thérapeute, par son attention bienveillante, respectant le rythme de l'enfant, en utilisant des imitations et des commentaires narratifs sur les expériences éprouvées par l'enfant, favorise ce sentiment d'exister et son intérêt pour l'autre.

C'est la voix qui attire l'attention de l'enfant lorsqu'elle est accordée de façon joyeuse et rythmée aux émotions et aux intérêts sensoriels ou esthétiques de l'enfant. La localisation spontanée de la voix qui est à l'origine de ces commentaires permet à l'enfant de s'intéresser au regard direct du visage de l'autre.

Mots clés: Autisme, narration, voix, regard

(Oír para poder observar dentro de la experiencia clínica del autismo. ¿De dónde viene la voz que me hace existir?)

Los niños autistas están, a menudo, totalmente absortos en la búsqueda de sensaciones que les hacen sentir que existen. Ellos evitan toda relación directa y no pueden interiorizar con seguridad su propia identidad. El lugar del terapeuta, en 


\begin{abstract}
ARTIGO
una atención cuidadosa, en el ritmo del niño, haciendo imitaciones y comentarios narrativos sobre experiencias vividas por el mismo, ayuda a desarrollar en el niño un sentimiento de existencia y un interés por el otro. Es la voz que llama la atención del niño, especialmente cuando esa voz se integra de forma alegre y rítmica a sus emociones y a sus intereses sensoriales o estéticos. La búsqueda espontánea de esa voz en el lugar de origen de los comentarios hace que el niño descubra un interés por la mirada directa hacia el rostro del otro.
\end{abstract}

Palabras clave: Autismo, narración, voz, mirada

(Zuhören, um einen Einblick in die Klinik des Autismus zu erhalten. Woher kommt die Stimme, die es mir ermöglicht zu existieren?)

Autistische Kinder sind oft ganz absorbiert von Empfindungen, die ihnen das Gefühl geben, zu existieren. Sie vermeiden direkten Augenkontakt und können die Sicherheit zu existieren nicht verinnerlichen. Anhand von sympathischer Aufmerksamkeit, dem Rhythmus des Kindes folgend, von Imitationen und erzählerischen Kommentaren über die Erfahrungen des Kindes weckt der Therapeut ein Gefühl des Daseins im Kind und ein Interesse am Andern. Es ist die Stimme, welche die Aufmerksamkeit des Kindes auf sich zieht, besonders wenn sie fröhlich und rhythmisch mit den Gefühlen des Kindes und seinen sensoriellen oder ästhetischen Interessen einhergeht. Die spontane Suche nach der Herkunft der Stimme, die hinter diesen Kommentaren steckt, regt das Kind an, direkt in das Gesicht des Anderen zu schauen.

Schlüsselwörter: Autismus, Erzählung, Stimme, Blick

(听闻能看透自闭症的临床学。让我存在的声音从哪儿来? )

自闭症儿童往往被那些让他感觉存在的感受所吸引住。他避免了直接的解 除而不能对存在有内在的安全感。治疗师的地方应以密切关注, 以孩子的节奏 模仿和叙述孩子的经历使他对他人产生兴趣。

儿童的注意有声音所引起, 只要这声音能愉快的与孩子的感情和美感融合在一 起。寻找叙述生命的声音会让孩子发现直接面对别人的兴趣。

关键词：自闭症, 叙述, 声音, 看见 
Citação/Citation: Lheureux-Davidse, Ch. (2015, dezembro). Ouvir para olhar na clínica do autismo. De onde vem a voz que me faz existir?. Revista Latinoamericana de Psicopatologia Fundamental, 18(4), 634-650.

Editores do artigo/Editors: Prof. Dr. Manoel Tosta Berlinck e Profa. Dra. Sonia Leite

Recebido/Received: 14.10.2014/ 10.14.2014 Aceito/Accepted: 12.12.2014 / 12.12.2014

Copyright: (C) 2009 Associação Universitária de Pesquisa em Psicopatologia Fundamental/ University Association for Research in Fundamental Psychopathology. Este é um artigo de livre acesso, que permite uso irrestrito, distribuição e reprodução em qualquer meio, desde que o autor e a fonte sejam citados / This is an open-access article, which permits unrestricted use, distribution, and reproduction in any medium, provided the original authors and sources are credited.

Financiamento/Funding: A autora declara não ter sido financiada ou apoiada / The author has no support or funding to report.

Conflito de interesses/Conflict of interest: A autora declara que não há conflito de interesses / The author has no conflict of interest to declare.

\section{Chantal Lheureux-Davidse}

MCF HDR Université Paris Diderot Paris 7 (Paris, França), UFR Etudes psychanalytiques, laboratoire CRPMS

59 rue du temple

75004 Paris, França

e-mail: chantal.1heureuxdavidse@laposte.net

This is an open-access article, which permits unrestricted use, distribution, the original authors and sources are credited. 